\title{
GEOLOGÍA Y EVOLUCIÓN MAGMÁTICA DEL ARCO DE SARAPIQUÍ, COSTA RICA
}

\author{
Esteban Gazel $^{1 *}$, Guillermo E. Alvarado ${ }^{1,2}$, Jorge Obando ${ }^{3}$ \& Arístides Alfaro ${ }^{2}$ \\ 1* Universidad de Costa Rica, Escuela Centroamericana de Geología, Apdo. 214-2060, Costa Rica. \\ egazel@geologia.ucr.ac.cr \\ 2 Instituto Costarricense de Electricidad, Geología, Apdo. 10032-1000. \\ ${ }^{3}$ Consultor, Hatillo 1, Calle Tempisque 130, San José. \\ * Dirección actual: Rutgers University, Department of Geological Sciences, 610 Taylor Road, \\ Piscataway, NJ 08854-8066 U.S.A. egazel@eden.rutgers.edu
}

(Recibido 7/7/05; Aceptado 13/2/06)

\begin{abstract}
The Sarapiquí Miocene Arc (22.2-11.4 Ma) is located in northern Costa Rica, Central America. The regional basement is represented by serpentinized peridotites, Albian siliceous pelagites and Paleocene to Middle Eocene turbidites. The units from this arc vary from olivine-bearing basalts to rhyolites, including lavas, pyroclastic deposits and lesser subvolcanic bodies. Based on geological mapping, K/Ar dating and geochemical analysis data the magmatic evolution of the Sarapiquí Arc is established in this paper: 1) Jardín Basalts (22.2 $\mathrm{Ma}$ ) show a near primary tendency with high $\mathrm{MgO}, \mathrm{TiO}_{2}, \mathrm{Ni}, \mathrm{Cr}$, and $\mathrm{Nb}$, high initial $\mathrm{La} / \mathrm{Yb}$ ratios, and low Ba/La. 2) The Arrepentidos Basaltic-andesites, Chaparrón Pyroclasts, Hito Sar Basalts, Boca Tapada Gabbro, and Chamorro Andesites (17.2-11.4 Ma). 3). Contemporaneous felsic magmas, produced by remelting of preexisting intrusives, originated the Crucitas rhyolites, characterizated by very high $\mathrm{Ba} / \mathrm{La}$ ratios and REE patterns that indicate a plagioclase rich, amphibole-bearing source. The $\mathrm{Zr} / \mathrm{Nb}$ ratios (7-36) show the coalition of a minor OIB source with a dominant MORB source, both modificated by subduction. An inverse model of the source using the REE of the mafic units, show that the mantle composition was a garnet peridotite. U/Th ratios $<1$, indicate that the mantle metasomatism was produced by subduction of carbonate pelagic sediments. Except the lowdegree melts included in the Jardín Basalts, the rest of the units show LILE and Pb enrichments and HFSE depletions, typical of the island arc environment.
\end{abstract}

Key words: Island arc, Sarapiquí arc, Miocene, geochemistry, magmatism.

RESUMEN: El Arco de Sarapiquí se localiza en el sector norte de Costa Rica. El basamento de esta región corresponde con peridotitas sepentinizadas, pelagitas silíceas del Albiano y turbiditas del Paleoceno-Eoceno Medio. Las unidades que forman este segmento del arco magmático del Mioceno (22,2-11,4 Ma) varían de basaltos olivínicos a riolitas, representadas por facies lávicas, depósitos piroclásticos y en menor proporción cuerpos subvolcánicos. Con base en el mapeo geológico, dataciones K/Ar y los análisis químicos se logró establecer la siguiente evolución magmática del Arco de Sarapiquí: 1) Los Basaltos Jardín (22,2 Ma) presentan una tendencia primaria con altos contenidos de $\mathrm{MgO}, \mathrm{TiO}_{2}, \mathrm{Ni}, \mathrm{Cr}$ y $\mathrm{Nb}$; altas razones $\mathrm{La} / \mathrm{Yb}$ y bajas razones $\mathrm{Ba} / \mathrm{La}$. 2) Posteriormente se originó un proceso de evolución del arco magmático (17,2-11,4 Ma), representado por los Andesitas-basálticas Arrepentidos, Piroclastos Chaparrón, Basaltos Hito Sar, Gabro Boca Tapada y Andesitas Chamorro 3) Magmas félsicos generados por fusión de rocas intrusivas preexistentes ricas 


\begin{abstract}
en plagioclasa y anfíbol, originaron las Riolitas Crucitas (16,4 Ma) caracterizada por altas razones Ba/La. Las razones $\mathrm{Zr} / \mathrm{Nb}$ evidencian la coalición de una fuente de tendencia OIB con una fuente dominante tipo MORB, modificadas por los procesos de subducción. Con excepción de los Basaltos Jardín originados por bajo grado de fusión parcial, las unidades de este arco muestran enriquecimientos en LILE y $\mathrm{Pb}$ así como deficiencias en HFSE, típicas de los ambientes de arcos de islas. Las razones U/Th $(<1)$ indican que el metasomatismo del manto se originó a partir de la subducción de sedimentos pelágicos carbonatados. Mediante un modelo inverso realizado con las unidades máficas del arco, se infiere que la composición del manto original corresponde con una peridotita con granate.

Palabras clave: Arco de islas, Arco de Sarapiquí, Mioceno, geoquímica, magmatismo.
\end{abstract}

\section{INTRODUCCIÓN}

El vulcanismo del Mioceno de América Central Austral ha sido poco estudiado a nivel regional en comparación con el arco volcánico actual (Carr et al., 1990; Feigenson \& Carr, 1993; Kussmaul et al., 1994; Cameron et al., 2002). Ehrenborg (1996) presenta una síntesis de las asociaciones magmáticas del Mioceno de Nicaragua, las cuales varían de basaltos a riolitas con una tendencia toleítica a calco-alcalina incluidas dentro del Grupo Coyol (24,3 - 11,7 Ma). Con base en la investigación anterior, Plank et al. (2002) muestran las primeras variaciones regionales de las relaciones $\mathrm{U} / \mathrm{Th}$ y $\mathrm{Ba} / \mathrm{La}$ de las rocas volcánicas del arco Coyol y la comparación de estas razones con el arco actual de Nicaragua.

En el sector sureste de Costa Rica, en la cordillera de Talamanca, afloran rocas plutónicas y volcánicas calco-alcalinas del Mioceno Superior. Dengo (1962) agrupó estas rocas dentro de la Serie Comagmática de Talamanca y menciona la posibilidad de que tengan un origen común. Posteriormente, De Boer et al. (1995) demuestran la afinidad geoquímica de estas rocas, las cuales se caracterizan por presentar un enriquecimiento en LILE (elementos litófilos de gran radio) y deficiencias en HFSE (elementos de alto equipotencial). La edad de estas rocas varía de 7,6-10,6 Ma en los alrededores de San Gerardo, el cerro Buena Vista, División y Buenos Aires, mientras que en los alrededores de Dominical y Puerto Nuevo las rocas gabroicas varían entre 11,76-17,50 Ma. En el sector noreste de la cordillera las edades de las granodioritas de los ríos Macho y Grande de Orosi oscilan de 3,6-4,2 Ma (MacMillan et al., 2004). Afloramientos pequeños de rocas plutónicas del Mioceno Superior-Plioceno afloran en los cerros de Escazú y Desmonte 7,9-2,1 Ma (Bellón \& Tournón, 1978, Saénz, 1982) y en la cordillera de Tilarán 3,9-7,1 Ma (Appel, 1990).

Tradicionalmente, se ha incluido el vulcanismo Neógeno de Costa Rica dentro del Grupo Aguacate. Posteriormente, este grupo se dividió en el sector del Valle Central en la Formación La Cruz (11,35-10,90 Ma), la cual presenta una composición basáltica a andesítica-basáltica de tendencia toleítica, originada en un arco de islas poco evolucionado y la Formación Grifo Alto (5,10-4,04 Ma) que incluye basaltos a andesitas originados en un arco de islas maduro calcoalcalino, separadas por una discordancia que documenta un evento tectónico que basculó la Formación la Cruz (Denyer \& Arias, 1991; Kussmaul et al., 1994; MacMillan et al., 2004). En la zona sur de Costa Rica, en los alrededores de Mano de Tigre afloran rocas basálticas (Mora, 1979) cuya edad es cercana a los $14 \mathrm{Ma}$ (MacMillan et al., 2004), sin embargo, sus características geoquímicas han sido poco estudiadas.

La región norte de Costa Rica, constituida por las llanuras de San Carlos y los Guatusos, ha sido una de las menos estudiadas desde el punto de vista geológico en Costa Rica. Sin embargo, esta región es el relicto de un arco magmático que se detallará en este trabajo desde un punto de vista geoquímico, geocronológico y litológico, con el propósito de analizar su origen y evolución.

\section{Trabajos previos en el Arco de Sarapiquí}

Hayes (1899) describe las rocas sedimentarias y volcánicas en los alrededores del río San Juán. Dengo (1962) interpreta esta región como una prolongación del graben de Nicaragua. 
Dóndoli (1965) menciona la existencia de una serie de antiguos focos volcánicos y posteriormente Malavassi \& Madrigal (1970) definen estas unidades volcánicas como la Formación Cureña. Descripciones petrográficas aisladas y unos pocos análisis químicos de estas lavas son presentados por Alvarado (1984) y Tournon (1984), evidenciando una amplia variedad petrográfica desde basaltos olivínicos hasta andesitas con hornblenda y una gama de facies volcánicas (tefras de caída, flujos piroclásticos, coladas de lava).

Astorga et al. (1991), con base en estudios geológicos y geofísicos detallados, denominan al sector norte de las llanuras de San Carlos como el Arco de Sarapiquí, correspondiendo con una unidad morfotectónica formada por rocas volcánicas del Neógeno que sobreyacen rocas sedimentarias del Paleógeno. Vargas \& Alfaro (1992) y Astorga (1992) describen la presencia de peridotitas serpentinizadas, basaltos alcalinos y rocas volcánicas félsicas (dacitas-riolitas) en la zona. Tournon et al. (1995) presentan datos geoquímicos sobre las peridotitas. Obando (1995) presenta un mapeo geológico, análisis químicos e isotópicos y dataciones K/Ar de las unidades ígneas. Por último, Sigarán (2001) presenta un estudio del prospecto minero Conchudita, que incluye análisis químicos de las rocas volcánicas.

\section{Metodología}

Dentro de las unidades cartografiadas se escogieron las muestras de las unidades lávicas más sanas y representativas. De las unidades predominantemente piroclásticas se muestrearon las coladas de lava subordinadas, ya que los piroclastos se encuentran alterados. En el Instituto de Geoquímica de la Universidad de Gotinga, Alemania, se realizaron 7 análisis de isótopos de $\mathrm{Sr}$ (Cuadro 1) con un espectrómetro Finingan MAT 262 (Cuadro 1), 29 análisis de XRF para la determinación de elementos mayores y trazas (Cuadros 2 y 3) y 7 análisis con un ICP-MS para la determinación de elementos de tierras raras (REE) y otras trazas (Cuadro 4). Las dataciones radioisotópicas que se presentan en este trabajo se realizaron mediante la técnica K/Ar (Cuadro 1). Los análisis químicos y dataciones K/Ar se tomaron de Obando (1995), los cuales se reinterpretan en este trabajo con base en los nuevos conocimientos geológicos y petrológicos después de una década de su propuesta original. Para la comparación de los resultados de esta investigación con los datos geoquímicos del arco volcánico actual de América Central se utilizó la base de datos CENTAM del programa IGPET 2004.

\section{Cuadro 1}

Dataciones radioisotópicas K/Ar y las razones de los isótopos de $\mathrm{Sr}$ para las unidades del Arco de Sarapiquí

\begin{tabular}{lcccc}
\hline Código & Unidad & Datación K/Ar en Ma & ${ }^{\mathbf{8 7}} \mathbf{S r} /{ }^{\mathbf{8 6}} \mathbf{S r}$ & Litología \\
\hline $4-1-95-6$ & Jardín & - & 0,70348 & Basalto \\
$29-1-95-3$ & Jardín & $22,2 \pm 1,5$ & 0,70349 & Basalto \\
$8-1-95-1$ & Arrepentidos & $17,2 \pm 0,8$ & 0,70361 & Andesita-basáltica \\
$7-1-95-1$ & Chaparrón & - & 0,70354 & Andesita \\
$25-1-95-3$ & Crucitas & - & 0,70383 & Dacita \\
$26-01-95-1$ & Crucitas & $14,3 \pm 0,5$ & - & Riolita \\
$6-1-95-3$ & Hito Sar & - & 0,70372 & Andesita-basáltica \\
$7-1-95-1$ & Hito Sar & $15,4 \pm 0,6$ & - & Andesita \\
Chamorro & Chamorro & $11,4 \pm 0,9$ & 0,70381 & Andesita \\
\hline
\end{tabular}




\section{Cuadro 2}

Resultados de las concentraciones (\%) de elementos mayores mediante XFR

\begin{tabular}{|c|c|c|c|c|c|c|c|c|c|c|c|c|}
\hline Código & Unidad & $\mathrm{SiO}_{2}$ & $\mathrm{TiO}_{2}$ & $\mathrm{Al}_{2} \mathrm{O}_{3}$ & $\mathrm{Fe}_{2} \mathrm{O}_{3}$ & MnO & MgO & $\mathrm{CaO}$ & $\mathrm{Na}_{2} \mathrm{O}$ & $\mathrm{K}_{2} \mathrm{O}$ & $\mathbf{P}_{2} \mathbf{O}_{5}$ & $\mathrm{H}^{2} \mathrm{O}^{+}$ \\
\hline $4-1-95-6$ & Jardín & 49,06 & 2,27 & 14,14 & 12,67 & 0,65 & 6,28 & 8,54 & 2,63 & 0,93 & 0,32 & \\
\hline $5-1-95-2$ & Jardín & 49,61 & 2,06 & 14,22 & 11,65 & 0,34 & 6,85 & 8,78 & 2,73 & 1,12 & 0,39 & \\
\hline $5-1-95-5$ & Jardín & 47,28 & 2,00 & 14,45 & 11,95 & 0,18 & 8,87 & 8,67 & 2,51 & 1,29 & 0,46 & 2,20 \\
\hline $23-1-95-2$ & Jardín & 49,80 & 2,23 & 13,93 & 12,75 & 0,26 & 6,57 & 8,84 & 2,80 & 0,87 & 0,31 & \\
\hline $29-1-95-3$ & Jardín & 49,21 & 0,88 & 16,58 & 10,88 & 0,19 & 7,39 & 9,61 & 2,23 & 0,32 & 0,17 & \\
\hline $5-1-95-10$ & Jardín & 51,47 & 1,03 & 17,08 & 11,31 & 0,24 & 4,55 & 8,26 & 2,90 & 1,12 & 0,23 & \\
\hline $8-1-95-3$ & Arrepentidos & 51,21 & 0,92 & 17,14 & 10,80 & 0,21 & 4,70 & 9,80 & 2,62 & 1,02 & 0,22 & \\
\hline $8-1-95-4$ & Arrepentidos & 54,24 & 1,01 & 17,59 & 9,53 & 0,24 & 3,54 & 7,70 & 3,56 & 0,95 & 0,30 & \\
\hline $7-1-95-1$ & Chaparrón & 51,78 & 0,86 & 17,26 & 9,09 & 0,18 & 5,03 & 10,05 & 2,36 & 1,16 & 0,23 & \\
\hline $7-1-95-3$ & Chaparrón & 52,26 & 0,84 & 17,57 & 9,36 & 0,21 & 4,90 & 9,31 & 2,82 & 0,84 & 0,19 & \\
\hline $4-1-95-3$ & Crucitas & 65,73 & 0,38 & 13,83 & 2,93 & 0,11 & 1,08 & 3,65 & 2,42 & 2,62 & 0,11 & 7,00 \\
\hline $25-1-95-3$ & Crucitas & 65,60 & 0,48 & 15,27 & 6,37 & 0,13 & 1,18 & 3,70 & 3,56 & 2,00 & 0,11 & \\
\hline $26-01-95-1$ & Crucitas & 70,11 & 0,27 & 14,82 & 2,19 & 0,13 & 0,56 & 1,94 & 3,58 & 3,12 & 0,04 & \\
\hline $28-1-95-1$ & Crucitas & 69,36 & 0,24 & 15,10 & 2,69 & 0,16 & 0,66 & 2,53 & 4,55 & 1,52 & 0,11 & \\
\hline $4-1-95-9$ & Hito Sar & 51,72 & 0,88 & 16,81 & 10,35 & 0,24 & 4,88 & 9,92 & 2,68 & 0,59 & 0,19 & 1,70 \\
\hline $5-1-95-1$ & Hito Sar & 51,89 & 0,93 & 19,50 & 9,59 & 0,14 & 2,79 & 9,37 & 3,00 & 0,99 & 0,22 & \\
\hline $5-1-95-7$ & Hito Sar & 49,98 & 1,05 & 18,10 & 10,78 & 0,20 & 4,21 & 9,53 & 2,74 & 0,99 & 0,24 & \\
\hline $5-1-95-11$ & Hito Sar & 50,68 & 1,08 & 17,78 & 10,81 & 0,37 & 3,83 & 9,38 & 2,74 & 1,07 & 0,27 & \\
\hline $6-1-95-2$ & Hito Sar & 48,10 & 0,68 & 22,20 & 8,38 & 0,15 & 4,78 & 11,68 & 1,96 & 0,52 & 0,15 & 1,50 \\
\hline $6-1-95-3$ & Hito Sar & 48,00 & 0,96 & 18,21 & 13,15 & 0,20 & 4,62 & 10,63 & 2,48 & 0,62 & 0,19 & \\
\hline $29-1-95-11$ & Hito Sar & 47,97 & 0,89 & 19,70 & 10,50 & 0,19 & 4,52 & 10,73 & 2,35 & 0,61 & 0,17 & \\
\hline $29-1-95-12$ & Boca Tapada & 48,97 & 0,73 & 19,53 & 9,11 & 0,17 & 5,54 & 11,27 & 2,46 & 0,62 & 0,21 & \\
\hline $4-1-95-7$ & Chamorro & 57,44 & 0,82 & 18,18 & 7,46 & 0,24 & 1,88 & 6,75 & 3,46 & 1,09 & 0,21 & \\
\hline 24-1-95-1 & Chamorro & 56,59 & 0,72 & 15,65 & 8,40 & 0,19 & 4,23 & 6,78 & 2,79 & 1,06 & 0,15 & \\
\hline $4-1-95-1$ & Chamorro & 58,18 & 0,98 & 16,18 & 7,32 & 0,16 & 2,30 & 5,85 & 3,11 & 2,43 & 0,35 & \\
\hline $4-1-95-2$ & Chamorro & 58,25 & 0,83 & 16,76 & 6,50 & 0,18 & 2,14 & 6,23 & 2,88 & 2,25 & 0,33 & \\
\hline $26-1-95-2$ & Chamorro & 58,32 & 0,84 & 17,48 & 7,31 & 0,21 & 1,72 & 5,12 & 3,27 & 1,19 & 0,15 & \\
\hline Chamorro & Chamorro & 53,71 & 0,93 & 18,38 & 7,56 & 0,17 & 2,25 & 7,52 & 3,05 & 1,46 & 0,43 & \\
\hline
\end{tabular}

Datos en ppm (ng/g). Las unidades litológicas son las mismas del Cuadro 2 
Cuadro 3

Resultados de las concentraciones elementos traza mediante XFR

\begin{tabular}{|c|c|c|c|c|c|c|c|c|c|c|c|c|}
\hline Código & Sc & $\mathrm{V}$ & $\mathrm{Cr}$ & $\mathrm{Co}$ & $\mathrm{Ni}$ & $\mathrm{Zn}$ & $\mathrm{Sr}$ & $\mathrm{Y}$ & $\mathrm{Rb}$ & $\mathrm{Zr}$ & $\mathrm{Ga}$ & $\mathrm{Nb}$ \\
\hline $4-1-95-6$ & 25 & 217 & 201 & 95 & 254 & 123 & 440 & 41 & 15 & 177 & 18 & 20 \\
\hline $5-1-95-2$ & 23 & 213 & 200 & 80 & 310 & 130 & 569 & 70 & 17 & 178 & 17 & 22 \\
\hline $5-1-95-5$ & 26 & 248 & 348 & 53 & 216 & 116 & 618 & 89 & 25 & 184 & 18 & 28 \\
\hline $23-1-95-2$ & 20 & 218 & 208 & 62 & 220 & 114 & 449 & 27 & 16 & 171 & 19 & 18 \\
\hline $29-1-95-3$ & 33 & 271 & 282 & 47 & 104 & 83 & 332 & 21 & 0 & 63 & 17 & 3 \\
\hline $5-1-95-10$ & 30 & 321 & 9 & 43 & 5 & 92 & 467 & 32 & 20 & 79 & 19 & 4 \\
\hline $8-1-95-3$ & 33 & 277 & 52 & 32 & 40 & 78 & 438 & 25 & 20 & 94 & 16 & 3 \\
\hline $8-1-95-4$ & 29 & 174 & 8 & 20 & 3 & 105 & 487 & 33 & 14 & 81 & 18 & 4 \\
\hline $7-1-95-1$ & 32 & 242 & 107 & 27 & 35 & 73 & 449 & 25 & 24 & 89 & 16 & 3 \\
\hline $7-1-95-3$ & 29 & 250 & 36 & 34 & 15 & 80 & 429 & 31 & 12 & 77 & 17 & 3 \\
\hline $25-1-95-3$ & 13 & 94 & 34 & 11 & 17 & 52 & 281 & 16 & 60 & 114 & 15 & 5 \\
\hline $26-01-95-1$ & 6 & 30 & 8 & 1 & 0 & 31 & 224 & 14 & 69 & 101 & 14 & 6 \\
\hline $4-1-95-3$ & 8 & 49 & 7 & 5 & 0 & 47 & 569 & 19 & 67 & 104 & 14 & 4 \\
\hline $28-1-95-1$ & 3 & 17 & 6 & 1 & 7 & 73 & 411 & 17 & 26 & 85 & 14 & 6 \\
\hline $4-1-95-9$ & 33 & 285 & 59 & 35 & 28 & 81 & 399 & 27 & 10 & 72 & 17 & 2 \\
\hline $5-1-95-1$ & 24 & 251 & 7 & 24 & 4 & 82 & 490 & 31 & 14 & 82 & 20 & 4 \\
\hline $5-1-95-7$ & 31 & 302 & 22 & 41 & 26 & 89 & 484 & 24 & 21 & 75 & 17 & 3 \\
\hline $5-1-95-11$ & 29 & 305 & 17 & 34 & 17 & 100 & 450 & 37 & 20 & 96 & 18 & 3 \\
\hline $6-1-95-2$ & 26 & 220 & 66 & 38 & 34 & 65 & 509 & 16 & 7 & 46 & 17 & 3 \\
\hline $6-1-95-3$ & 33 & 321 & 57 & 35 & 50 & 83 & 471 & 22 & 11 & 60 & 19 & 4 \\
\hline $29-1-95-11$ & 30 & 305 & 15 & 31 & 18 & 81 & 484 & 21 & 6 & 53 & 20 & 2 \\
\hline $29-1-95-12$ & 30 & 224 & 95 & 36 & 52 & 74 & 508 & 18 & 9 & 60 & 19 & 2 \\
\hline $4-1-95-7$ & 23 & 127 & 9 & 20 & 13 & 90 & 377 & 36 & 15 & 92 & 19 & 5 \\
\hline $24-1-95-1$ & 25 & 196 & 37 & 26 & 20 & 76 & 399 & 26 & 34 & 96 & 16 & 5 \\
\hline $4-1-95-1$ & 20 & 148 & 8 & 12 & 4 & 89 & 394 & 47 & 54 & 161 & 17 & 8 \\
\hline $4-1-95-2$ & 20 & 118 & 11 & 16 & 4 & 80 & 515 & 37 & 110 & 161 & 17 & 9 \\
\hline $26-1-95-2$ & 24 & 184 & 26 & 23 & 22 & 78 & 316 & 28 & 17 & 129 & 17 & 9 \\
\hline Chamorro & 9 & 135 & 25 & 10 & 45 & 86 & 489 & 41 & 71 & 154 & 18 & 8 \\
\hline
\end{tabular}


Cuadro 4

Resultados de las concentraciones elementos traza y REE mediante ICP-MS

\begin{tabular}{lrrrrrrrrrrrrrr}
\hline Código & Li & $\mathrm{Sc}$ & $\mathrm{Rb}$ & $\mathrm{Sr}$ & $\mathrm{Y}$ & $\mathrm{Cs}$ & $\mathrm{Hf}$ & $\mathrm{Ta}$ & $\mathrm{Pb}$ & $\mathrm{Th}$ & $\mathrm{U}$ & $\mathrm{Ba}$ & $\mathrm{La}$ \\
\hline 4-1-95-6 & 4,19 & 22,13 & 23,56 & 374,99 & 35,74 & 0,17 & 3,98 & 1,11 & 4,35 & 2,08 & 0,74 & 279,80 & 20,99 \\
29-1-95-3 & 6,06 & 30,15 & 3,41 & 358,72 & 16,32 & 0,08 & 1,30 & 0,19 & 8,68 & 0,37 & 0,21 & 220,18 & 5,61 \\
$6-1-95-3$ & 4,93 & 31,51 & 8,66 & 407,13 & 17,02 & 0,15 & 1,21 & 0,20 & 5,29 & 0,45 & 0,27 & 245,34 & 5,77 \\
$7-1-95-1$ & 5,00 & 29,63 & 31,88 & 392,99 & 19,67 & 1,95 & 1,91 & 0,38 & 11,97 & 0,91 & 0,49 & 385,70 & 8,93 \\
4-1-95-3 & 3,74 & 5,80 & 63,31 & 413,24 & 14,63 & 2,61 & 2,21 & 0,56 & 6,21 & 2,24 & 0,95 & 1258,92 & 10,35 \\
8-1-95-3 & 5,99 & 30,36 & 22,60 & 382,24 & 21,59 & 0,48 & 2,14 & 0,40 & 7,67 & 1,16 & 0,60 & 411,74 & 9,40 \\
Chamorro & 5,64 & 15,66 & 105,12 & 391,60 & 32,56 & 2,15 & 4,12 & 0,41 & 4,68 & 2,19 & 1,05 & 695,22 & 15,29
\end{tabular}

\begin{tabular}{lrrrrrrrrrrrrr}
\hline Código & Ce & Pr & Nd & Sm & Eu & Gd & Tb & Dy & Ho & Er & Tm & Yb & Lu \\
\hline 4-1-95-6 & 43,70 & 6,39 & 27,49 & 6,81 & 2,17 & 6,95 & 0,95 & 5,39 & 1,07 & 2,81 & 0,37 & 2,10 & 0,31 \\
29-1-95-3 & 12,67 & 2,06 & 9,33 & 2,68 & 0,92 & 2,82 & 0,44 & 2,82 & 0,60 & 1,73 & 0,25 & 1,68 & 0,27 \\
6-1-95-3 & 13,43 & 2,23 & 10,49 & 3,12 & 1,07 & 3,25 & 0,48 & 3,00 & 0,63 & 1,76 & 0,27 & 1,69 & 0,27 \\
7-1-95-1 & 19,69 & 3,13 & 13,89 & 3,75 & 1,21 & 3,89 & 0,56 & 3,41 & 0,72 & 2,05 & 0,30 & 1,93 & 0,31 \\
4-1-95-3 & 21,79 & 2,68 & 10,68 & 2,43 & 1,03 & 2,75 & 0,37 & 2,26 & 0,48 & 1,45 & 0,24 & 1,64 & 0,27 \\
8-1-95-3 & 20,87 & 3,29 & 14,80 & 4,00 & 1,21 & 4,07 & 0,59 & 3,66 & 0,76 & 2,18 & 0,33 & 2,12 & 0,33 \\
Chamorro & 36,01 & 5,44 & 24,05 & 6,30 & 1,75 & 6,32 & 0,92 & 5,62 & 1,17 & 3,43 & 0,51 & 3,29 & 0,52 \\
\hline
\end{tabular}

Datos en ppm (ng/g). Las unidades litológicas son las mismas del Cuadro 2.

\section{CONTEXTO GEOLÓGICO}

Se presenta un mapa simplificado del Arco de Sarapiquí (Fig. 1) y litologías asociadas, donde se incluyen las siguientes unidades:

\section{Peridotita serpentinizada y pelagitas silíceas}

Las peridotitas serpentinizadas se encuentran en afloramientos aislados en el sector noroeste del arco (Fig. 1). Corresponden con harzburgitas con cromita y microfracturas con hematita (Vargas \& Alfaro, 1992). Estas rocas son correlacionables con las serpentinitas sobreyacidas por pelagitas síliceas rojas de edad Albiano, encontradas a $1965 \mathrm{~m}$ de profundidad en el pozo de exploración petrolera Tonjibe (Pizarro, 1993). Además, se pueden correlacionar con peridotitas asociadas con radiolaritas reportadas por Astorga (1992), para la zona de Sábalos en Nicaragua y con las peridotitas de Santa Elena. Estas correlaciones muestran que el basamento del Arco de Sarapiquí está constituido por rocas ultramáficas serpentinizadas cuyo emplazamiento presenta una edad mínima preAlbiano (Tournon et al., 1995).

\section{Formación Machuca}

Definida por Hayes (1899), aflora en las riberas del río San Juan en el sector norte del arco (Fig. 1). Se compone de intercalaciones de lutitas, limolitas y en menor grado areniscas finas, las cuales son generalmente gris azuladas, silicificadas, con ausencia de macrofósiles y de bioturbación. La estratificación varía de mediana a fina $(10$ a $30 \mathrm{~cm})$, de tipo ondulante con acuñamientos laterales, gradación positiva, laminación 

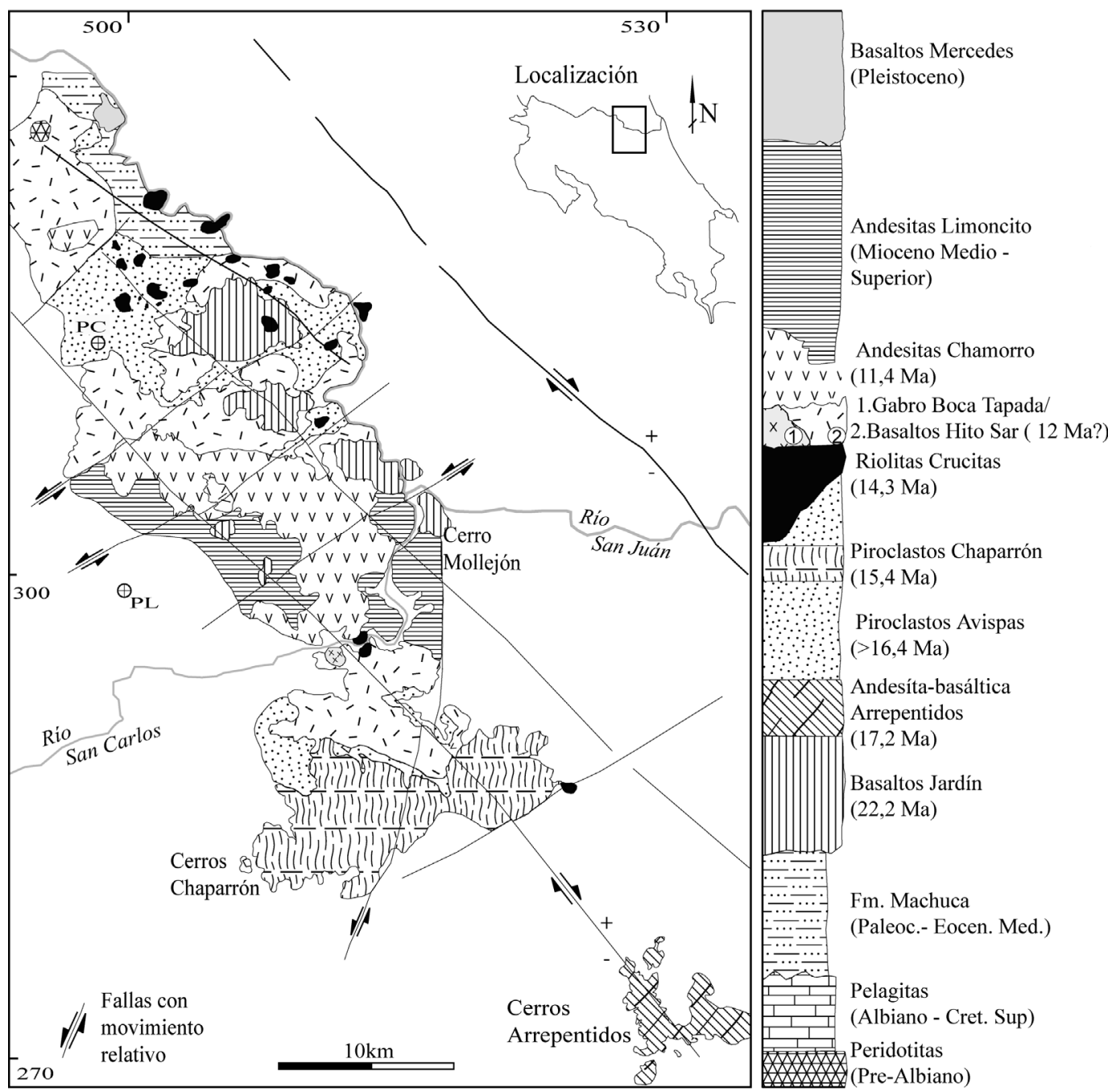

Fig. 1. Mapa sinóptico de las principales litologías del Arco de Sarapiquí (modificado de Obando, 1995). La columna estratigráfica a la derecha muestra las relaciones cronoestratigráficas de las diferentes unidades geológicas. El Arco de Sarapiquí incluye las unidades magmáticas del Mioceno (22,2-11,4 Ma), las litologías más antiguas representan el basamento y los Basaltos Cerro Mercedes son independientes a la evolución de este arco. En blanco se muestran las áreas con suelos volcánicos residuales y materiales aluviales no detallados en este trabajo.

paralela fina y estructuras de carga de las facies limolitícas o arenosas sobre las lutitas. Corresponden con turbiditas y otros depósitos de talud. En el lado nicaragüense son sobreyacidas por rocas volcanoclásticas del OligocenoMioceno del Grupo Tamarindo y rocas volcánicas del Mioceno del Grupo El Coyol (Weyl, 1980). En el lado costarricense, estas rocas son sobreyacidas discordantemente por las rocas volcánicas del Arco de Sarapiquí. La edad de la Formación Machuca es de Paleoceno-Eoceno Medio (Hayes, 1899; Malavassi \& Madrigal, 1970)

\section{Basaltos Jardín}

Esta unidad aflora ampliamente en el área central y noroeste del arco (Fig. 1). Está constituida por 
basaltos con megafenocristales de olivino (3$5 \%$ ) con inclusiones de espinela cromífera y golfos de corrosión o reabsorción; trazas de plagioclasa, clinopiroxeno, magnetita y de biotita, en una matriz pilotaxítica a intersertal compuesta por microlitos de plagioclasa, clinopiroxeno, olivino, minerales opacos y en ocasiones vidrio. Presenta un espesor mínimo de $250 \mathrm{~m}$. Su edad $\mathrm{K} / \mathrm{Ar}$ es Mioceno Inferior temprano (22,2 $\pm 2,7$ Ma), constituyendo la unidad más antigua del vulcanismo del arco.

\section{Andesitas-basálticas Arrepentidos}

Se encuentran expuestas en el área sureste del arco (Fig. 1). Son principalmente andesitasbasálticas porfiríticas, con hasta $31 \%$ de fenocristales de plagioclasa y clinopiroxeno, y un $3 \%$ de olivino sano o cloritizado. La matriz es intergranular, traquítica o intersertal, formada por microlitos de plagioclasa, clinopiroxeno, magnetita y ocasionalmente olivino. Además, incluye andesitas poco porfiríticas con $<11 \%$ de fenocristales (plagioclasa $8 \%$ y minerales opa$\cos 3 \%$ ) que en ocasiones presentan clorita, calcita y seladonita como minerales secundarios. Esta unidad también agrupa andesitas con clinopiroxeno con textura holocristalina intergranular seriada, con un $9-17 \%$ de fenocristales y microfenocristales de plagioclasa (labradorita-bitownita) y piroxeno. Un espesor mínimo de $160 \mathrm{~m}$ puede ser estimado para esta unidad. La edad $\mathrm{K} / \mathrm{Ar}$ la ubica en el Mioceno Inferior tardío $(17,2 \pm 0,8 \mathrm{Ma})$.

\section{Piroclastos Avispas}

Aflora en la zona noroeste y central del arco (Fig. 1). Está representada por depósitos piroclásticos félsicos de flujos de bloques y cenizas, flujos de pómez, oleadas piroclásticas, depósitos de caída y lavas dacíticas-riolíticas. Su espesor varía de 75 a $100 \mathrm{~m}$ con base en los datos de perforación en el prospecto minero Crucitas (De la Cruz, 1994; Sigarán, 2001). La edad mínima de esta unidad con base en las relaciones de campo y en dataciones K/Ar de un concentrado de adularia $(16,4 \pm 0,4 \mathrm{Ma})$ es Mioceno Inferior tardío a Mioceno Medio temprano (Obando, 1995).

\section{Piroclastos Chaparrón}

Se encuentran expuestos en los cerros Chaparrón, en el área central sur del arco (Fig. 1). Corresponde con una secuencia de flujos de bloques y cenizas, oleadas piroclásticas y coladas de lava subordinadas. La composición de los bloques del flujo de bloques y ceniza y de la coladas son similares, correspondiendo con andesitas basálticas con dos piroxenos y olivino $(<2 \%)$, con textura hipocristalina porfirítica y una matriz intersertal; además presenta hematita, limonita y calcita como minerales secundarios. Su espesor mínimo es de $260 \mathrm{~m}$ y la edad K/Ar la ubica en el Mioceno Medio Temprano (15,4 \pm 0,6 Ma).

\section{Riolitas Crucitas}

Aflora en cerros aislados en la parte norte del arco (Fig. 1). Son dacitas a riolitas con anfíbol y/o biotita. La textura es hipocristalina-porfirítica, con fenocristales subhedrales de plagioclasa con zonación oscilatoria fuerte (hasta un $30 \%)$, cuarzo reabsorbido $(<5 \%)$, biotita $(<4 \%)$, magnetita $(<3 \%)$ y hornblenda verde (hasta un $10 \%$ ) ocasionalmente opacitizada, con trazas de clinopiroxeno, apatito y circón. La matriz está compuesta de vidrio café claro en proceso de desvitrificación y tiene una textura perlítica. Un espesor mínimo aflorante de esta unidad se puede estimar en $100 \mathrm{~m}$. La edad K/Ar de esta unidad es Mioceno Medio tardío (14,3 \pm 0,5 Ma).

\section{Basaltos Hito Sar}

Afloran en la parte central del arco en forma continua, aunque también más hacia el noroeste en forma aislada (Fig. 1). Presentan una textura porfirítica, con abundantes megafenocristales de plagioclasa (10-20\%), olivinos, comúnmente cloritizados (4-7\%), clinopiroxenos con estructuras 
de reloj de arena (1-3\%) y magnetita $(<1 \%)$, en una matriz que varía de intergranular a intersertal constituida por microlitos de plagioclasa, clinopiroxeno y minerales opacos. El espesor mínimo es de $225 \mathrm{~m}$. Aunque no se realizaron dataciones $\mathrm{K} / \mathrm{Ar}$, en la parte basal de las perforaciones en el sector Prospecto Crucitas esta unidad corta los Piroclastos Avispas (De La Cruz, 1994), por lo tanto tienen una edad inferior a 15,3 Ma. Con base en las relaciones estratigráficas y la razón de los isótopos de $\mathrm{Sr}$, Obando (1995) estimó una edad aproximada de 12 Ma para esta unidad.

\section{Gabro Boca Tapada}

Afloran en la margen derecha del río San Carlos (Fig. 1), en los alrededores del poblado de Boca Tapada, y hasta la fecha representan las únicas rocas intrusivas observadas en el arco. Se clasifican como leucogabros con olivino, con una textura holocristalina-hipidiomórfica constituída por fenocristales de plagioclasa (72 $\%)$, cristales hipidiomórficos de clinopiroxenos (20\%), olivino (5\%) y magnetita (3\%). Posiblemente representa las fases plutónicas del magmatismo que constituye los Basaltos Hito Sar y por lo tanto se infiere una edad de Mioceno Medio tardío.

\section{Andesitas Chamorro}

Agrupa a una serie de coladas andesíticas que afloran principalmente en la parte noreste y central norte del arco. Son andesitas piroxénicas que presentan una textura holocristalina porfirítica, con fenocristales de plagioclasas (25-40\%), clinopiroxenos $(2-5 \%)$, ortopiroxenos $(1-4 \%)$ y magnetita $(<2 \%)$ en una matriz de microlitos de plagioclasa, piroxenos, magnetita, trazas de anfíbol parcialmente cloritizado y en ocasiones vidrio pardo. Esta unidad sobreyace por medio de una discordancia angular las rocas piroclásticas de la Unidad Avispas. La edad K/Ar la ubica en el Mioceno Medio tardío hasta Superior temprano $(11,4 \pm 0,4 \mathrm{Ma})$.

\section{Andesitas Limoncito}

Esta unidad fue descrita con base en muestras del pozo estratigráfico Limoncito $(570 \mathrm{~m}$ de profundidad, Fig. 1) perforado por RECOPE en 1986. La secuencia inferior de $490 \mathrm{~m}$ corresponde con interestratificaciones de lavas andesíticas piroxénicas de 5 a $40 \mathrm{~m}$ de espesor con flujos piroclásticos de menor espesor. En el pozo Chamorro (Fig. 1) esta unidad se ubica desde los 0 a los $189 \mathrm{~m}$ y corresponde con una secuencia de rocas piroclásticas y coladas de lava subordinadas que sobreyacen a las andesitas Chamorro. Con base en criterios estratigráficos y las relaciones de campo, la edad inferida de la unidad es Mioceno Medio Tardío a Superior Temprano.

\section{Basaltos Mercedes}

En el cerro Mercedes (Fig. 1), en el sector norte del arco, afloran basaltos alcalinos (basanita leucitítica) constituidos por fenocristales de olivino idiomórfico con inclusiones de espinela cromífera en una matriz con abundante clinopiroxeno, plagioclasa y en menor cantidad leucita idiomórfica y augita titanífera. Estas lavas son ricas en xenolitos de peridotita, con estructura granuda-poligonal con juntas triples y sin foliación, constituida por olivino, ortopiroxeno, clinopiroxeno y espinela cromífera, que posiblemente representan una muestra del manto actual existente bajo Costa Rica. Esta unidad presenta un espesor de $350 \mathrm{~m}$. Tanto las basanitas como lo xenolitos están frescos, lo que permite inferir una edad pleistocena para esta unidad.

\section{GEOQUIMICA}

Los resultados analíticos de los elementos mayores y trazas se resumen en los Cuadros 2, 3 y 4. Las rocas volcánicas del Arco de Sarapiquí presentan una composición química que varía de basaltos a riolitas (Fig. 2). El diagrama AFM evidencia una tendencia que varía de toleítica a calco-alcalina (Fig. 3). Los Basaltos Jardín se agrupan dentro de la serie toleítica, en donde 


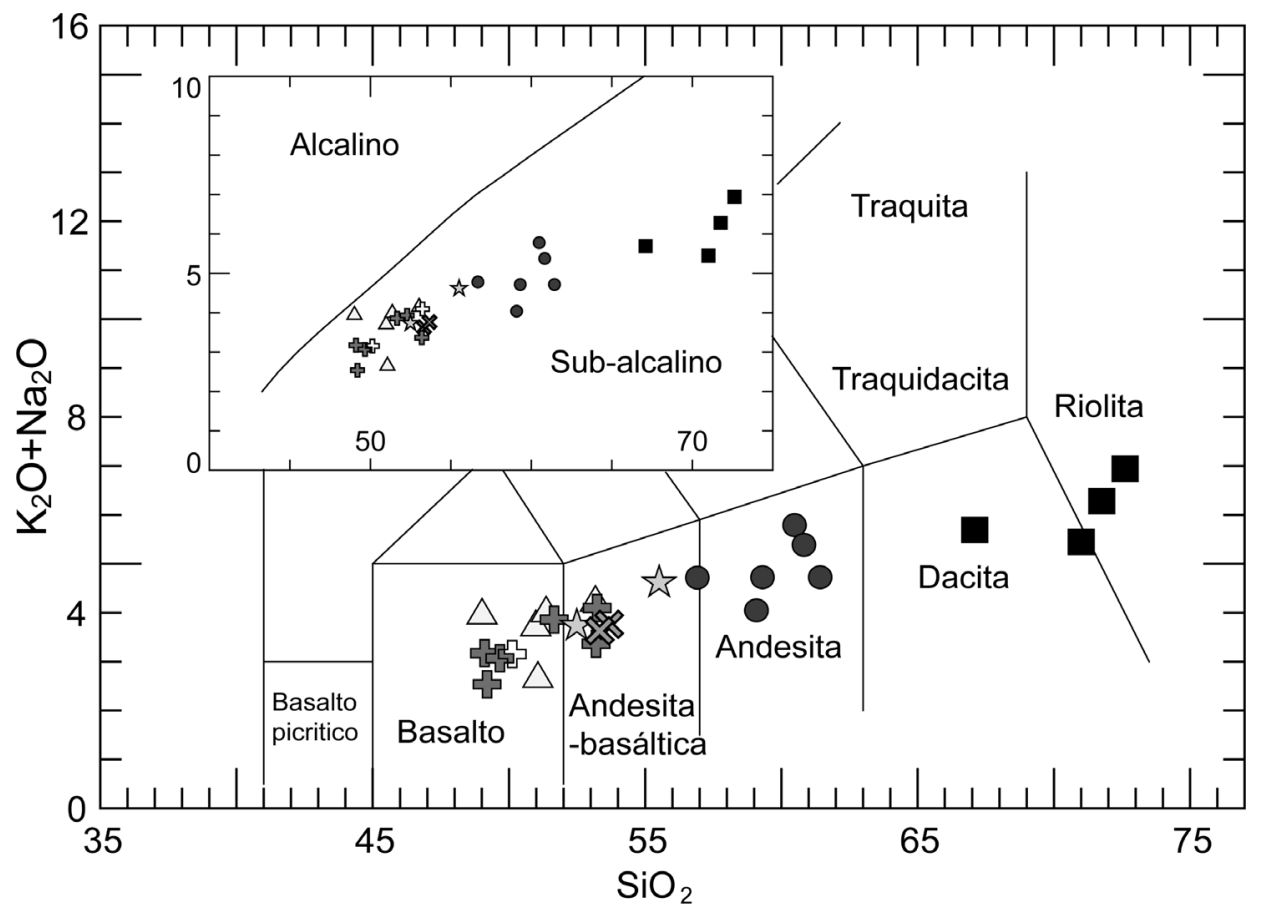

\ Piroclástos Chaparrón (15,4 Ma)

Riolitas Crucitas (14,3 Ma)

Andesitas-basálticas

Arrepentidos (17,2 Ma)

乡 Basaltos Hito Sar (12 Ma)

ङ Gabro Boca Tapada

$\triangle$ Basaltos Jardín (22,2 Ma)

- Andesitas Chamorro (11,3 Ma)

Fig. 2. Diagrama Álcalis Totales/Sílice (TAS) utilizado para la clasificación geoquímica de las unidades del Arco de Sarapiquí. Inserto se encuentra el diagrama para discriminar entre las series alcalinas y sub-alcalina.

tanto el $\mathrm{TiO}_{2}$ como el $\mathrm{Fe}_{2} \mathrm{O}_{3}$ aumentan con la diferenciación en esta unidad; este incremento es propio del estilo de diferenciación de las series toleíticas, no obstante los altos valores de $\mathrm{Na}_{2} \mathrm{O}$ y $\mathrm{K}_{2} \mathrm{O}$ de los Basaltos Jardín sugieren la posibilidad de un componente alcalino en la génesis de esta unidad. La transición a la serie calco-alcalina se aprecia en el resto de las unidades de composición máfica a intermedia, sin embargo, no muestran un aumento en el contenido de $\mathrm{Fe}_{2} \mathrm{O}_{3}$ y $\mathrm{TiO}_{2}$ al disminuir el $\mathrm{MgO}$, lo que indica que el estilo de diferenciación posterior a los Basaltos Jardín es predominantemente calco-alcalino (Fig. 3).

La tendencia máfica a intermedia encontrada en la mayoría de las rocas del arco permite utilizar el contenido de $\mathrm{MgO}$ para analizar los

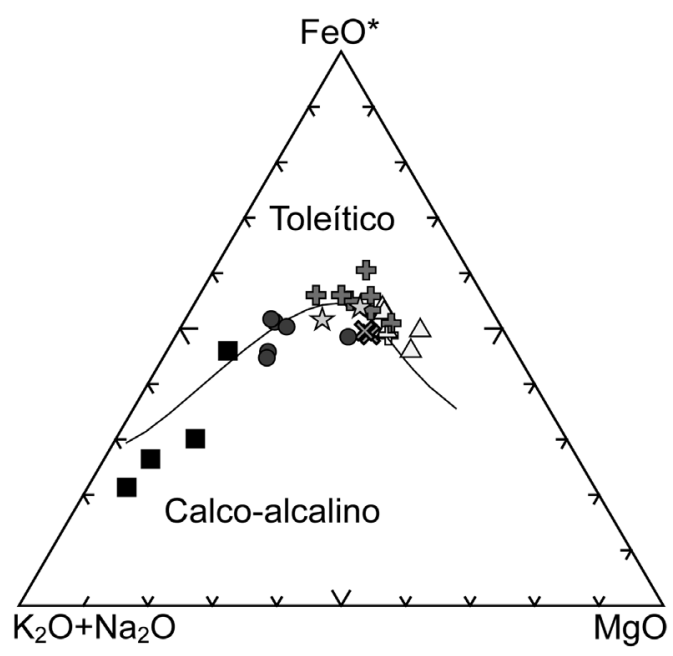

Fig. 3. Diagrama AFM para diferenciar las series toleíticas y calco-alcalinas. La simbología es la misma de la figuras 2 . 
procesos de diferenciación. Los elementos mayores de las rocas analizadas muestran una buena correlación general con el $\mathrm{MgO}$, en donde la concentración de $\mathrm{SiO}_{2}, \mathrm{Na}_{2} \mathrm{O}$ y $\mathrm{K}_{2} \mathrm{O}$ aumenta al decrecer el contenido de $\mathrm{MgO}$ (Fig. 4). Por otra parte, los porcentajes de $\mathrm{Fe}_{2} \mathrm{O}_{3}, \mathrm{CaO}$, y $\mathrm{TiO}_{2}$ muestran una correlación positiva, típica de los óxidos compatibles (Fig. 4).

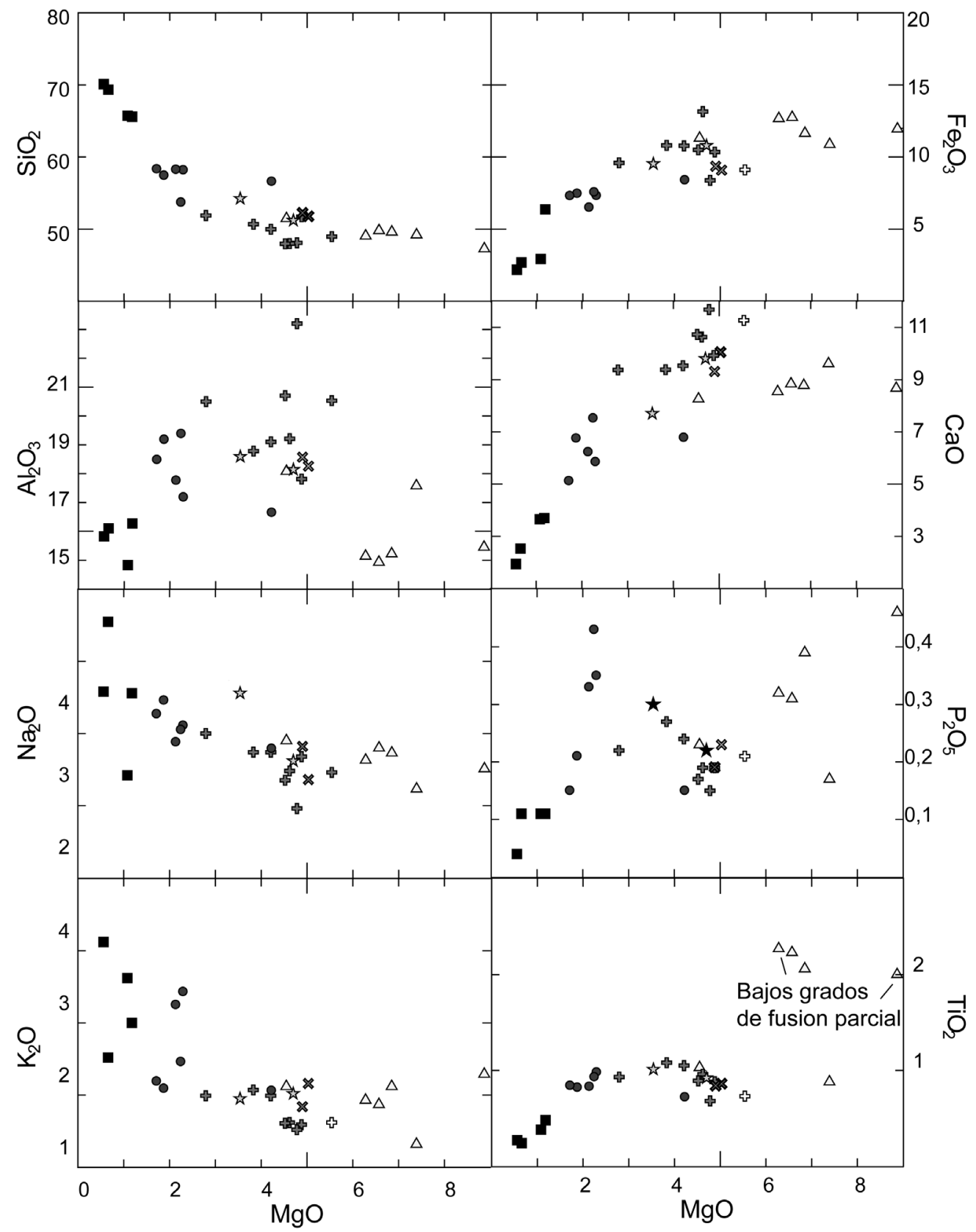

Fig. 4. Diagramas de variación de elementos mayores utilizando $\mathrm{MgO}$ como índice de diferenciación. La simbología es la misma de la figura 2. 
Para la construcción de los diagramas de variación con elementos traza, tambien se utilizó el $\mathrm{MgO}$ como índice de diferenciación. El Ni, Cr, $\mathrm{Co}$ y Sc muestran correlaciones positivas con el $\mathrm{MgO}$, evidenciando su carácter compatible, mientras que el $\mathrm{Zr}$ y $\mathrm{Nb}$ presentan tendencias negativas atribuidas a su carácter incompatible (Fig. 5). En los diagramas anteriores se aprecia como las muestras de los Basaltos Jardín representan una población diferente del resto de las unidades del arco, tanto en elementos mayores como en trazas.

\section{DISCUSIÓN}

\section{Evolución del Arco de Sarapiquí}

Los procesos magmáticos durante el Mioceno iniciaron en la zona norte de Costa Rica hace unos 22 Ma con los Basaltos Jardín. Estas rocas muestran una afinidad geoquímica de magmas primarios, poco usual para un ambiente de arco de islas. Las muestras menos fraccionadas presentan altos contenidos de $\mathrm{MgO}(6,28-8,87 \%), \mathrm{TiO}_{2}(2,00-$ $2,27 \%), \mathrm{Nb}$ (18-28 ppm), Ni (216-310 ppm), Cr

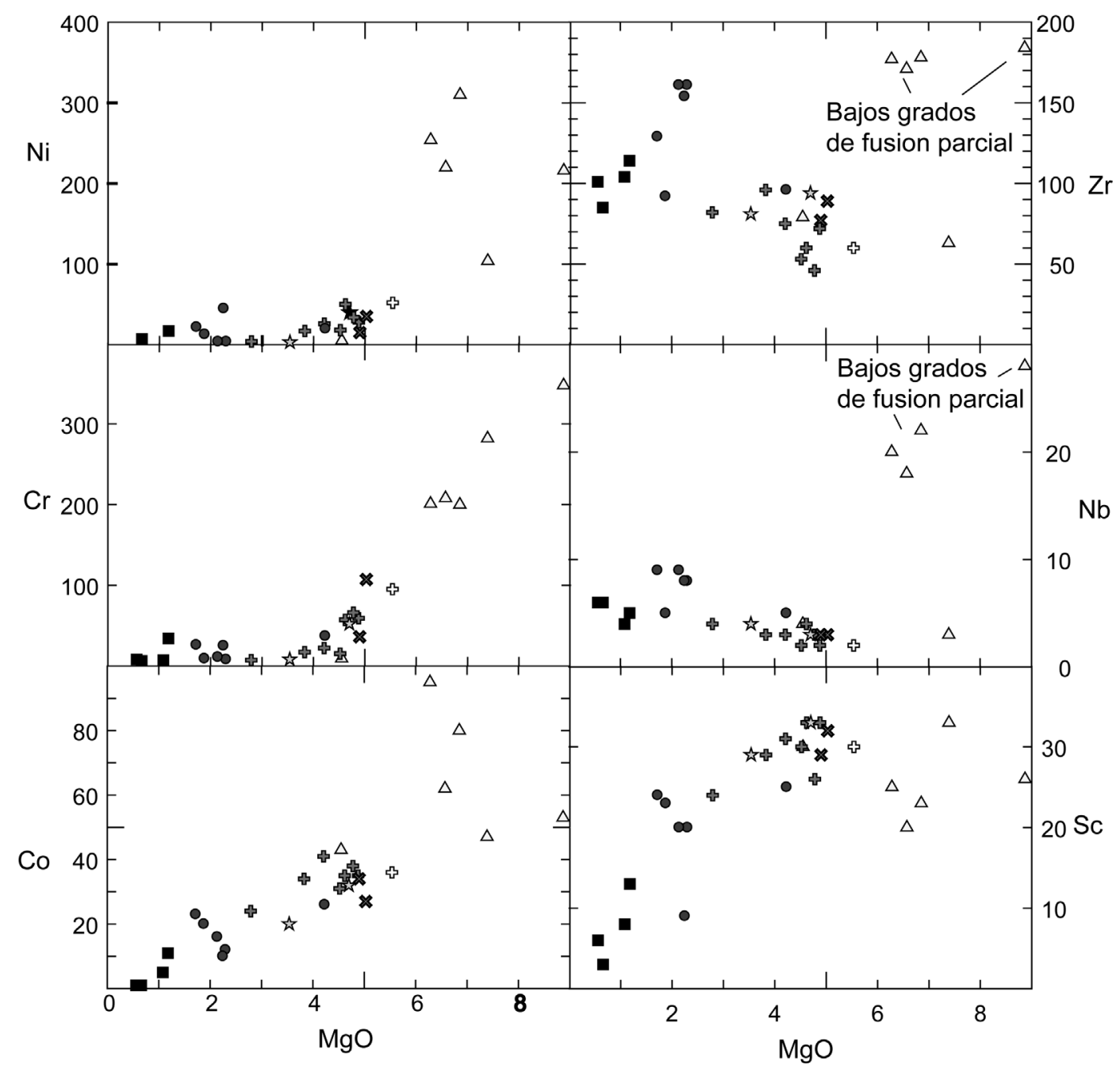

Fig. 5. Diagramas de variación de elementos traza seleccionados utilizando MgO como índice de diferenciación. La simbología es la misma de la Fig. 2. 
(201-348 ppm) y Zr (171-184 ppm) (Figs. 4 y 5). Esta unidad se originó por bajos grados de la fusión parcial, posiblemente por medio de descompresión provocada por una tectónica extensiva. Este mecanismo de fusión ha sido sugerido para rocas con altos contenidos de $\mathrm{MgO}, \mathrm{TiO}_{2}$ y $\mathrm{Nb}$ del arco volcánico cuaternario centroamericano (Cameron et al., 2002). Los REE de los Basaltos Jardín, normalizados a condritos (Fig. 6A), muestran dos tendencias de fusión parcial. La primera presenta un patrón con una pendiente fuerte, que evidencia un enriquecimiento en REE livianos originado a partir de bajos grados de fusión parcial. La razón $\mathrm{La} / \mathrm{Yb}$ es relativamente alta $\sim 10$, en comparación con el resto de las muestras analizadas, lo cual respalda un origen a partir de bajos grados de fusión parcial (Fig. 7). La razón $\mathrm{Ba} / \mathrm{La}(13,3)$ se encuentra dentro del promedio de esta relación en el manto $\sim 15$ (Sun $\&$ MacDonough, 1989), lo que indica que el aporte de los fluidos de la placa subducida fue muy limitado y el mecanismo de fusión predominante
A)

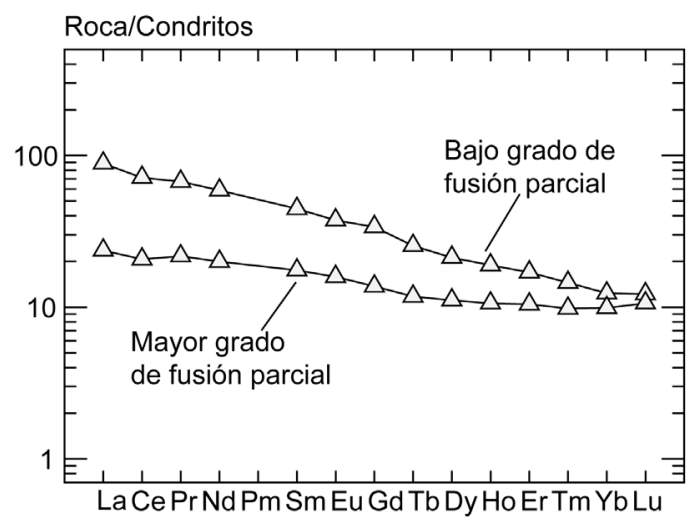

C)

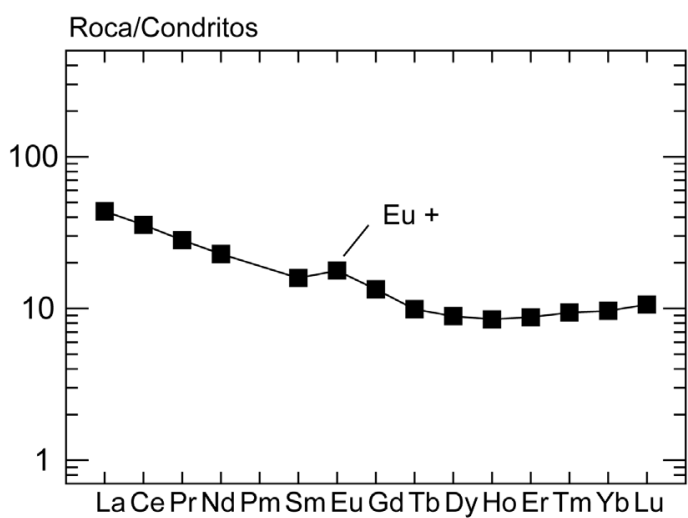

B)

Roca/Condritos

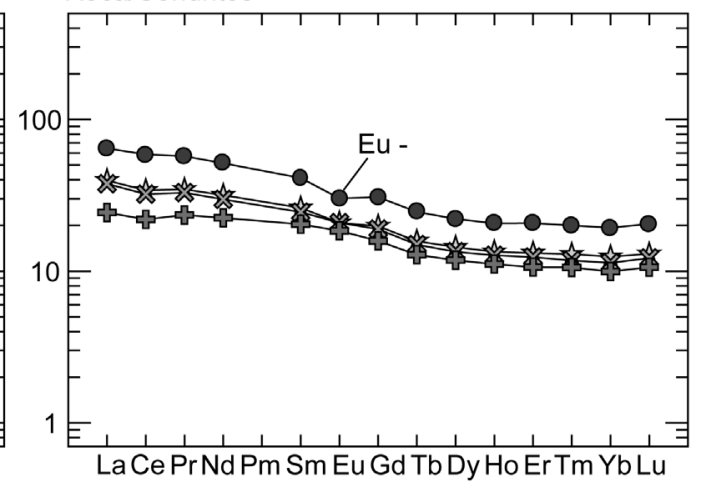

D)

Roca/Manto primitivo

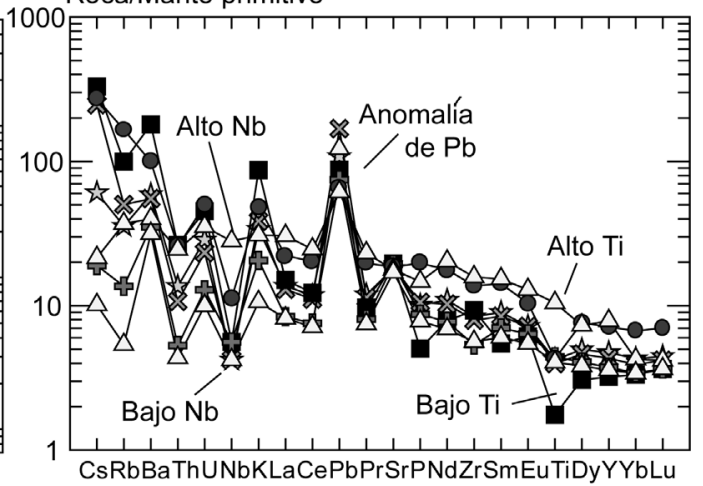

Fig. 6. Diagramas spider de las diferentes muestras de las unidades del Arco de Sarapiquí, normalizaciones según Sun \& MacDonough (1989). A) Diagrama spider de los REE de los Basaltos Jardín normalizados a condritos donde se muestra los dos grados de fusión parcial dentro de esta unidad. B) Diagrama spider de los REE de las Andesítas-basálticas Arrepentidos (estrellas), de las coladas andesíticas-basálticas dentro de los Piroclastos Chaparrón (equis), de los Basaltos Hito Sar (cruces) y de las Andesitas Chamorro (círculos). C) Diagrama spider de los REE de las Riolitas Crucitas normalizados a condritos, se aprecia un patrón cóncavo hacia abajo y una anomalía positiva de Eu. D) Diagrama spider de las unidades anteriores normalizadas a un manto primitivo, con excepción de los basaltos de tendencia primitiva incluidos en los Basaltos Jardín. Se observa un enriquecimiento en LILE y Pb y deficiencias en HFSE. 


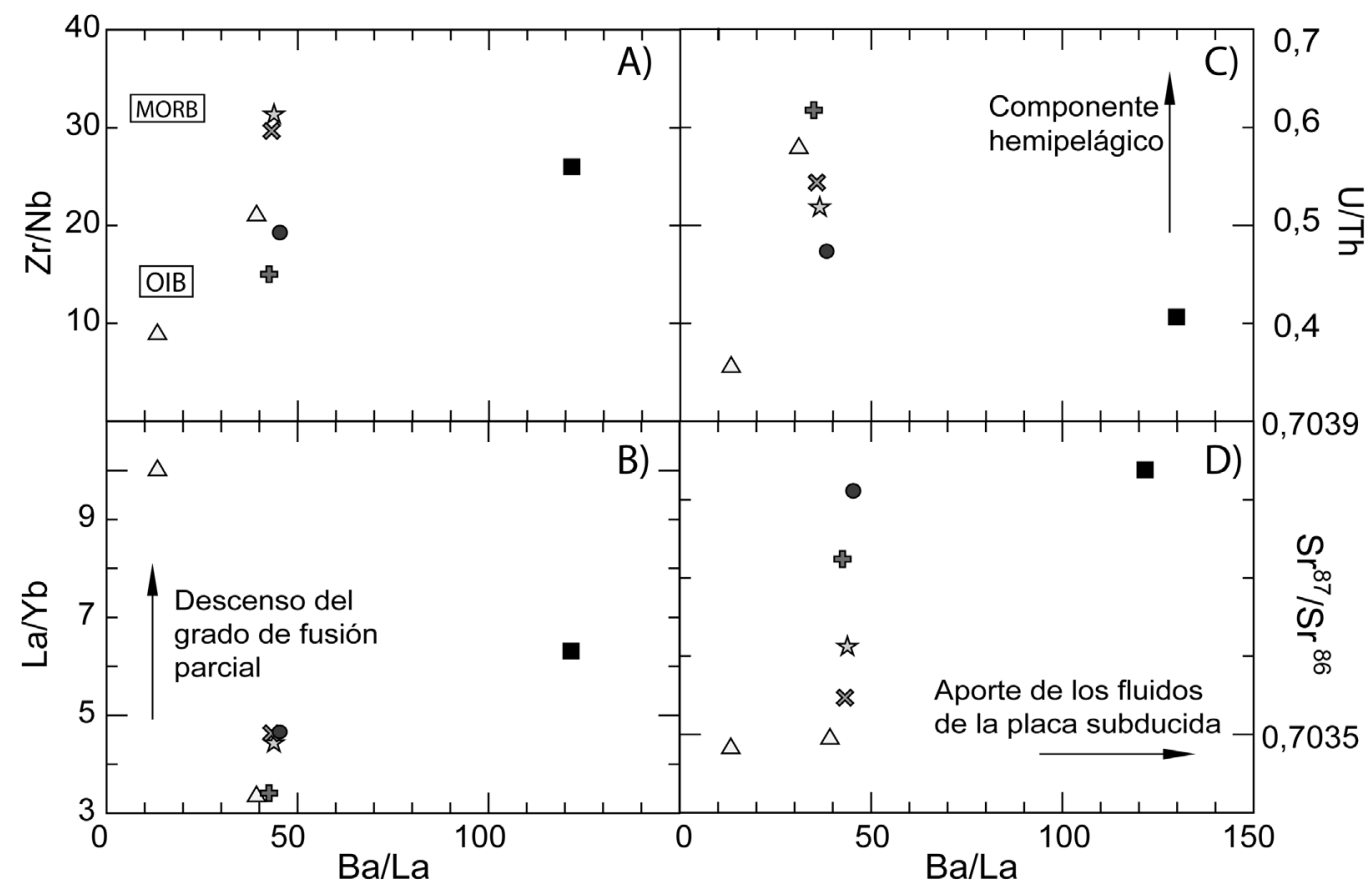

Fig. 7. Razones $\mathrm{Zr} / \mathrm{Nb}, \mathrm{La} / \mathrm{Yb}, \mathrm{U} / \mathrm{Th}$ y $\mathrm{Sr}^{87} / \mathrm{Sr}^{86} \mathrm{vrs} \mathrm{Ba/La}$, en todos el aporte de los fluidos de la placa subducida se incrementa hacia la derecha. La simbología es la misma de la Fig. 2. A) Se muestra los valores promedio de las razones $\mathrm{Zr} / \mathrm{Nb}$ y $\mathrm{Ba} / \mathrm{La}$ para las fuentes mantelicas OIB y MORB y los valores de las muestras del Arco de Sarapiquí. B) La relación $\mathrm{La} / \mathrm{Yb}$ aumenta al disminuir el grado de fusión parcial, la muestra de los Basaltos Jardín de tendencia primaria presenta el menor grado de fusión parcial. C) La razón U/Th $(<1)$ indica que el aporte de los fluidos de la placa subducida fue a partir de sedimentos pelágicos carbonatados. D) La razón de los isótopos de $\mathrm{Sr}^{87} / \mathrm{Sr}^{86}$ aumenta con el incremento de la relación $\mathrm{Ba} / \mathrm{La}$, sin embargo el rango se encuentra dentro de los OIB.

fue la descomprensión del manto. La segunda tendencia presenta un patrón subhorizontal (Fig. 6) que sugiere un mayor grado de fusión parcial, con una relación La/Yb mas baja $\sim 3$. El aumento en la razón $\mathrm{Ba} / \mathrm{La}$ (Fig. 7) sugiere un incremento en metasomatismo del manto en respuesta a un mayor aporte de los fluidos de la placa subducida.

Las Andesitas basálticas Arrepentidos (17,2 Ma), las coladas andesíticas-basálticas incluidas dentro de los Piroclastos Chaparrón (15,4 Ma), los Basaltos Hito Sar (12 Ma) y las Andesitas Chamorro (11,3 Ma) representan la evolución geoquímica y litológica del Arco de Sarapiquí. Estas unidades presentan un patrón de los REE subhorizontal, con un ligero enriquecimiento en los REE livianos (Fig. 6 B.). El patrón de los REE de las Andesitas Chamorro presenta una anomalía negativa de Eu, que evi- dencia un mayor fraccionamiento de plagioclasas que en el resto de las unidades (Fig. 6 B.). Las bajas razones $\mathrm{La} / \mathrm{Yb}(3,4-6,4)$ indican que el grado de fusión parcial del manto fue relativamente alto (Fig. 7).

Las Riolitas Crucitas (14,3 Ma) se caracterizan por presentar un patrón de REE normalizados a condritos (Fig. 6 C) cóncavo hacia abajo, que evidencia un equilibrio con anfíbol y una anomalía positiva de Eu que indica que la fuente se encontraba enriquecida en plagioclasas (Haskin, 1984). Esta fuente no está presente en ninguna otra unidad del arco lo que permite interpretar que esta unidad se originó por medio de fusión a nivel cortical de plutones en vías de enfriamiento, los cuales entraron en contacto con magmas basálticos en ascenso. Un modelo de fusión similar ha sido propuesto para rocas volcánicas félsicas pliopleistocenas de Costa Rica (Vogel et al., 2004). 


\section{Aporte de los componentes de la placa subducida}

En los últimos años se ha investigado el aporte de los fluidos producto de la deshidratación de la placa subducida en el origen de los magmas de los arcos de islas. Se ha reconocido que los elementos litófilos de gran radio (LILE) como el Sr, K, Ba y otros elementos móviles como el $\mathrm{Pb}$ son aportados por los fluidos de la placa subducida al metasomatizar el manto. Por otra parte, la poca incorporación de $\mathrm{Be}, \mathrm{Th}$ y $\mathrm{Nb}$, indica que la fusión (reciclaje) de sedimentos es un proceso limitado y que la deshidratación de los sedimentos es el proceso más común. Una de las conclusiones más importantes muestra que los sedimentos hemipelágicos presentan enriquecimientos en $\mathrm{Ba}$ y $\mathrm{U}$, mientras que los sedimentos pelágicos carbonatados solo se encuentran enriquecidos en $\mathrm{Ba}$. La utilización de las razones $\mathrm{U} / \mathrm{Th}$ y $\mathrm{Ba} / \mathrm{La}$ permite entonces conocer el tipo de sedimento que aportó los fluidos en la generación de rocas ígneas en un ambiente de arco magmático (Patino et al., 2000).

Las muestras del Arco de Sarapiquí presen$\tan$ razones U/Th bajas $(0,4-0,6)$, que indican que el metasomatismo del manto se originó a partir de la subducción de sedimentos pelágicos carbonatados (Fig. 7). Las razones U/Th coinciden con el rango reportado por Plank et al. (2002) para el Arco Coyol (24-7 Ma) de Nicaragua. Este aporte está relacionado con la subducción de sedimentos pelágicos carbonatados, depositados antes del inicio del cierre del istmo centroamericano hace aproximadamente 10 Ma (Plank et al., 2002), a partir del cual la sedimentación varió de pelágica carbonatada a hemipelágica. Esta variación del tipo de aporte aumentó la razón U/Th $(>1)$ de las rocas postmiocénicas del arco volcánico de América Central (Patino et al., 2000; Plank et al. 2002).

La razón de $\mathrm{Ba} / \mathrm{La}$ de las Riolitas Crucitas es muy alta $\sim 120$ (Fig. 7), lo que indica que la fuente presentó un aporte importante de los fluidos de subducción o que esta se encontraba bastante diferenciada. Sin considerar los valores anómalos de las Riolitas Crucitas, el rango de las relaciones $\mathrm{Ba} / \mathrm{La}(39,3-47,5)$ es bastante estable (Fig. 7), indicando que el aporte de los fluidos de la placa subducida fue constante y no varió significativamente durante la evolución del Arco de Sarapiquí

Al comparar las muestras de las unidades de composición máfica a intermedia del Arco de Sarapiquí con los datos del arco volcánico actual de América Central (Fig. 8), se aprecia cómo la muestras del Arco de Sarapiquí presentan razones $\mathrm{Ba} / \mathrm{La}$ y $\mathrm{La} / \mathrm{Yb}$ similares al segmento norte del arco actual de Costa Rica (Cordillera de Guanacaste) (Fig. 8). Esto sugiere la posibilidad que los fluidos con $\mathrm{Ba}$ proveniente de la placa subducida han sido constantes durante los últimos 20 Ma y por lo tanto el grado de fusión parcial no ha variado significativamente en este periodo de tiempo. Este patrón ha sido reportado de manera análoga para el Arco Coyol de Nicaragua, donde las relaciones $\mathrm{Ba} / \mathrm{La}$ son bastante similares a los segmentos del arco actual de ese país (Plank et al., 2002).

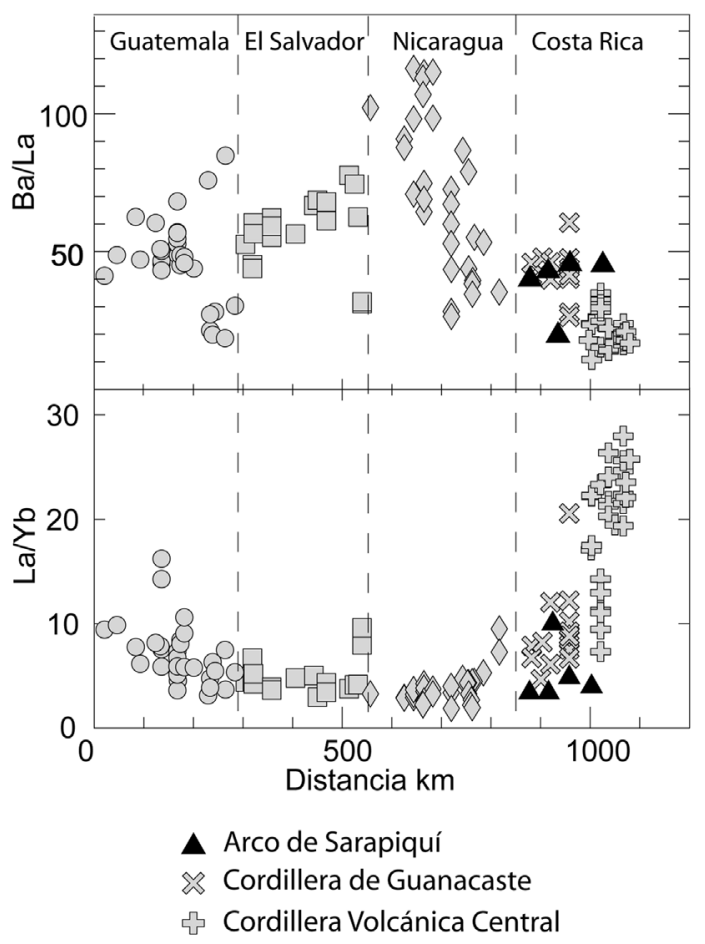

Fig. 8. Comparación de los datos del Arco de Sarapiquí con el Arco Volcánico de América Central. 


\section{Fuente mantélica}

Como se muestra en la figura 7, las razones de $\mathrm{Zr} / \mathrm{Nb}$ varian entre 7-36 lo que evidencia la participación de un manto heterogéneo, producto de la interacción de una fuente mantélica menor OIB (Ocean-Island Basalt), evidente en los Basaltos Jardín originados por bajos grados de fusión parcial, con una fuente predominante MORB (Mid-Ocean Ridge Basalt), ambas modificadas por los procesos de subducción. Las razones isótopicas $\mathrm{Sr}^{87} / \mathrm{Sr}^{86}$ aumentan con la relación $\mathrm{Ba} / \mathrm{La}$, aunque continúan dentro del rango de los OIB (Zindler \& Hart, 1986) (Fig. 7); no obstante, son necesarios futuros análisis de isótopos de $\mathrm{Nd}$ y $\mathrm{Pb}$ para detallar más la fuente. Con excepción de los Basaltos Jardín originados a partir de un bajo grado de fusión parcial, el resto de las unidades del arco muestran las típicas deficiencias HFSE (Ti y Nb, Fig. 6 D) de los ambientes de arco de islas. Un modelo posible consiste en diferentes episodios de fusión y extracción en la zona de trasarco y la incorporación posterior de material residual deficiente dentro de la fuente bajo la zona del arco (Woodhead et al., 1993).

Para la determinación de la fuente mantélica se realizó un modelo inverso (según Feigenson \& Carr, 1993) con los REE de las unidades máficas (Basaltos Jardín, Andesitas-basálticas Arrepentidos y Basaltos Hito Sar). Con base en el patrón de los resultados, la concentración promedio (modelos 2, Fig. 9) muestra una distribución razonable de los REE pesados, reflejada tanto en la composición del líquido y como en la de la fuente. Según este modelo se infiere que el manto que origino estas unidades tenia una composición modal de $25 \%$ cpx $+50 \%$ ol $+10 \%$ opx $+15 \%$ ga (Fig. 9). Durante la realización del modelo se utilizaron unidades de diferentes edades que presentaron muy buenas líneas de regresión, lo que podría implicar que el manto no presentó variaciones importantes en un periodo de unos $10 \mathrm{Ma}$.

\section{Distribución de los arcos del Mioceno}

La distribución de los arcos del Mioceno ha sido un tema en discusión que continua en la actualidad. De acuerdo con los datos geocronológicos de Alvarado et al. (1992), De Boer et al. (1995), las nuevas dataciones Ar/Ar de Plank et al. (2002), MacMillan et al. (2004) y con los datos presentados en este trabajo, se propone la siguiente distribución de los arcos magmáticos durante el Mioceno en el sector de Costa Rica y Nicaragua (Fig. 10). Los arcos de Sarapiquí, Coyol (Nicaragua) y las rocas plutónicas y efusivas de la Cordillera de Talamanca representan un magmatismo del Mioceno Inferior-Mioceno Medio que se incluyen en este trabajo en el Arco Coyol-Talamanca. Las Formaciones Bagaces, La Cruz y Grifo Alto del Grupo Aguacate y las rocas plutónicas y efusivas de la cordillera de Tilarán se incluyen en el Arco Aguacate, que representa el magmatismo del Mioceno Superior-Plioceno. Como se muestra en la figura 10 existe un salto de $30^{\circ}$ (Gans et al., 2002) entre los ejes de estos dos arcos durante el Mioceno Medio-Mioceno

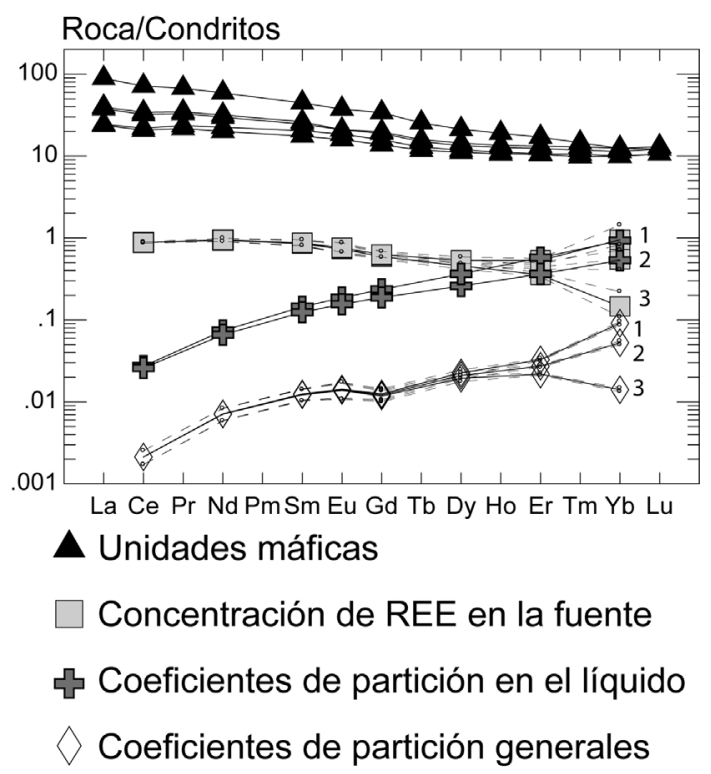

Fig. 9. Diagrama spider normalizado a condritos del resultado del modelo inverso con las unidades máficas del Arco de Sarapiquí: Basaltos Jardín, Andesitas Arrepentidos y Piroclástos Chaparrón. Las líneas punteadas muestran el rango de error de los resultados. Los modelos resultantes son: 1) $25 \% \mathrm{cpx}+50 \% \mathrm{ol}+15 \% \mathrm{opx}+10 \% \mathrm{ga}$, 2) $25 \% \mathrm{cpx}+50 \% \mathrm{ol}+10 \% \mathrm{opx}+15 \% \mathrm{ga}, 3) 25 \% \mathrm{cpx}$ $+50 \%$ ol $+5 \%$ opx $+20 \%$ ga. Normalización según Sun \& MacDonough (1989). 


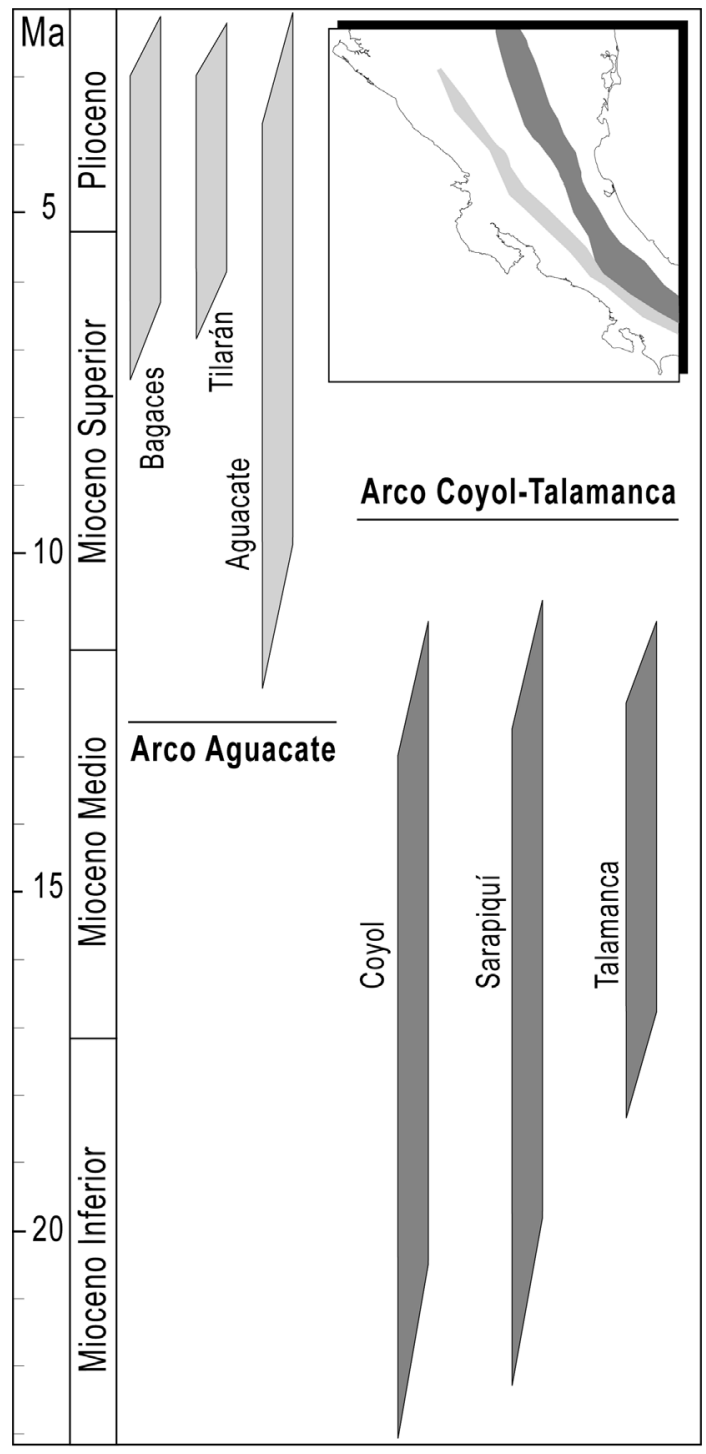

Fig 10. Comparación cronológica de los arcos magmáticos durante el Mioceno en Costa Rica y Nicaragua.

Superior. Este salto posiblemente responde a variaciones del ángulo de la placa subducida y coincide con la ruptura de la placa "detached slab" a niveles mantélicos que provocó levantamientos epirogénicos y variaciones espaciales del vulcanismo de América Central (Rogers et al., 2002). Es importante realizar mapeo, estudios estratigráficos y geoquímicos que permitan establecer las relaciones genéticas y la evolución regional de cada arco. Además debe realizarse una redefinición de las formaciones y miembros que componen estos arcos con el fin de evitar diversidad innecesaria de términos a nivel local y regional.

\section{CONCLUSIONES}

El Arco de Sarapiquí (22,2-11,4 Ma) representa un segmento del arco magmático del Mioceno de Costa Rica, cuyas asociaciones magmáticas varían desde basaltos a riolitas.

Los Basaltos Jardín, presentan una composición química que evidencia un carácter primario; el mecanismo de fusión se interpreta como una decomprensión del manto en respuesta a una tectónica extensiva, que posteriomente presentó un aporte de los fluidos de la placa subducida. Dentro de esta unidad se encuentran dos tendencias de fusión parcial: la primera evidencia bajos grados de fusión parcial y un aporte limitado de los fluidos de la placa subducida y la segunda presenta un mayor grado de fusión parcial, en respuesta a un aumento en el aporte de los fluidos de la placa subducida.

Las Andesitas basálticas Arrepentidos, los Piroclastos Chaparrón, los Basaltos Hito Sar y las Andesitas Chamorro representan los productos de los procesos evolutivos del Arco de Sarapiquí. El grado de fusión parcial fue relativamente alto y el componente de la placa subducida se mantuvo estable durante el periodo de tiempo en que se originaron estas unidades. Las Riolitas Crucitas, se originaron a partir de fusión de rocas intrusivas preexistentes ricas en plagioclasa y con presencia de anfíbol.

El metasomatismo del manto se originó a partir de la subducción de sedimentos pelágicos carbonatados, depositados antes del inico del cierre del istmo centroamericano. Las muestras del Arco de Sarapiquí presentan las mismas razones $\mathrm{Ba} / \mathrm{La}$ y $\mathrm{La} / \mathrm{Yb}$ que el segmento norte del arco volcánico actual de Costa Rica, lo que sugiere que el flujo de fluidos con Ba proveniente de la placa subducida se ha mantenido constante los últimos $20 \mathrm{Ma}$.

Las evidencias geoquímicas sugieren la coalescencia de una fuente mantélica menor OIB 
con una fuente MORB, ambas modificadas por los procesos de subducción. Mediante un modelo inverso con los REE de las unidades máficas se determinó que esta fuente corresponde con una peridotita con granate.

\section{AGRADECIMIENTOS}

Se agradece a la Compañía Minera Industrias Infinito por su autorización para utilizar los análisis químicos, isotópicos y dataciones K/Ar. A los profesores Michael J. Carr, Lina C. Patino, Siegfried Kussmaul, Kaj Hoernle y Percy Denyer por sus oportunos comentarios y revisiones. Un agradecimiento especial a Gerardo Soto y María I. Sandoval por las detalladas revisiones, que mejoraron significativamente esta publicación.

\section{REFERENCIAS}

ALVARADO, G.E., 1984: Aspectos petrológicos-geológicos de los volcanes y unidades lávicas del Cenozoico Superior de Costa Rica. - 183 págs. Univ. de Costa Rica [Tesis de Lic.].

ALVARADO, G.E., KUSSMAUL, S., CHIESA, S., GILLOT, P.-Y., WÖRNER, G. \& RUNDLE, C., 1992: Resumen cronoestratigráfico de las rocas ígneas de Costa Rica, basado en dataciones radiométricas. - J. South Amer. Earth Sci. 6(3): 151-168.

APPEL, H., 1990: Geochemie und K/Ar-Datierungen an Magmatiten in Costa Rica, Zentralamerika. -149 págs., Johannes Gutenberg-Universität, Mainz [Tesis PhD].

ASTORGA, A., 1992: Descubrimiento de la corteza oceánica mesozoica en el norte de Costa Rica y sur de Nicargua. - Rev. Geol. América Central, 13: 25-59.

ASTORGA, A., FERNÁNDEZ, J.A., BARBOZA, G., CAMPOS, L., OBANDO, J., AGUILAR, A. \& OBANDO, L.G., 1991: Cuencas sedimentarias de Costa Rica: Evolución geodinámica y potencial de hidrocarburos. Rev. Geol. América Central, 13: 25-59

BELLON, H. \& TOURNON, J., 1978: Contribution de la géochronométrie K-Ar à l'étude du magmatism de Costa Rica, Amérique Central. - Bul. Soc. Géol. France, 20(6): 955-959.

CAMERON, B.I., WALTER, J.A., CARR, M.J., PATINO, L.C., MATIAS,O. \& FEIGENSON, M.D., 2002: Flux versus decompression melting at stratovolcanoes in southeastern Guatemala. - J. Volcanol. Geoth. Res. 119: $21-50$

CARR, M.J., FEIGENSON, M.D. \& BENNETT, E.A., 1990: Incompatible element and isotopic evidence for tectonic control of source mixing and melt extraction along the Central American arc. - Contrib. Mineral. Petrol. 105: 369-380.

DE BOER, J.Z., DRUMOND, M., BORDELON, M.J., DEFANT, M.J., BELLON, H \& MAURY, R. C., 1995: Cenozoic magmatic phases of the Costa Rica island arc (Cordillera de Talamanca). - En: MANN, P. (ed.): Geologic and tectonic development of the Caribbean plate boundary in southern Central America. - Geol. Soc. Amer. Spec. Pap. 295: 35-55.

DE LA CRUZ, R., 1994: Estudio de secciones estratigráficas. Sondajes CP-1 a CP-24, Proyecto Crucitas. - 43 págs. Placer Dome de Costa Rica [Informe interno].

DENGO, G., 1962: Tectonic-igneuos sequence in Costa Rica. - En: ENGEL, A. E. J., JAMES, H. J. \& LEONARD, B. F. (eds.): A volume to honor A. F. Budington - Geol. Soc. Amer. Spec. Vol.: 133-161.

DENYER, P. \& ARIAS, O., 1991: Estratigrafía de la región central de Costa Rica. - Rev. Geol. América Central, 12: 1-59.

DONDOLI, C., 1965: Información general geológico-petrográfica y mineralógica sobre Costa Rica. - 17 págs. Inf. Tec. y Notas Geol. 4 (18): DGMP-MEIC, San José.

EHRENBORG, J., 1996: A new stratigraphy for the Tertiary volcanic rocks of the Nicaraguan Higthland. Geol.Soc. Amer. 108 (7): 830 - 842.

FEIGENSON, M.D. \& CARR, M. J., 1993: The source of Cental American lavas: inferences from a geochemical inverse modeling. - Contrib. Min. Petrol. 113: 226 235

GANS, P.B., MACMILLAN, I., ALVARADO, G., PÉREZ, W. \& SIGARÁN, C., 2002: Neogene evolution of the Costa Rican arc. - Abstr. Programs - Geol. Soc. Amer. 34, 136.

HASKIN, L.A., 1984: Petrogenetic modelling - use of rare earth elements. - En: HENDERSON, P.: Rare earth elements geochemistry, 510 págs. Elsevier, Amsterdam.

HAYES, W., 1899: Physiography and geology of the region adjacent to the Nicaragua canal route. - Geol. Soc. Amer. Bull. 10: 285-348 
IRVINE, T.N. \& BARAGAR, W.R.A., 1971: A guide to the chemical classification of the common volcanic rocks. - Can. J. Earth Sci. 8: 523-548.

KUSSMAUL, S., TOURNON, J., \& ALVARADO, G., 1994: Evolution of the Neogene to Quaternary igneous rocks of Costa Rica. - Profil, 7: 97-123.

MACMILLAN, I. GANS, P. B. \& ALVARADO. G.E., 2004: Middle Miocene to present plate tectonic history of the southern Central American volcanic arc. Tectonophys. 392: 325 - 348

MALAVASSI, E. \& MADRIGAL R., 1970. Reconocimiento geológico de la zona norte de Costa Rica. - Inf. Téc. y Notas Geol. 9 (38): 1-12, Direc. Geol. Min. Petról; San José.

MORA, S., 1979: Estudio geológico de una parte de la región sureste del Valle del General, Provincia de Puntarenas, Costa Rica. - 3 vol. Univ. de Costa Rica [Tesis de Lic.].

OBANDO, J., 1995: Estudio geológico del Arco de Sarapiquí: Contribución a las nuevas exploraciones mineras de la región. - 74 págs. Placer Dome de Costa Rica [Informe interno].

PATINO, L.C., CARR, M.J. \& FEIGENSON, M.D., 2000: Local and regional variations in the Central American arc lavas controlled by variations in subducted sediment input. - Contrib. Mineral. Petrol. 138: 265-283.

PIZARRO, D., 1993: Los pozos profundos perforados en Costa Rica: aspectos litológicos y bioestratigráficos. Rev. Geol. Amér. Central, 15: 81-85.

PLANK, T., VAUGHN, B. \& CARR, M,J. 2002: Nicaraguan volcanoes record paleoceanographic changes accompanying closure of the Panama gateway. - Geology, 30 (12): 1087-1090.

ROGERS, R.D., KARÁSON,H. \& VAN DER HILST, R. D., 2002: Epeirogenic uplift above a detached slab in northern Central America. - Geol. Soc. Amer. 30 (11): 1031-1034.
SÁENZ, R., 1982: Edades radiométricas de algunas rocas ígneas de Costa Rica. - Bol. Vulcanol., 12: 8-10. UNA, Heredia.

SIGARÁN, C., 2001: Caracterización vulcanológica y alteración hidrotermal del yacimiento aurífero de Conchudita (Zona Norte, Costa Rica). - 132 págs. Univ. de Costa Rica [Tesis de Lic.].

SUN, S.-S. \& MACDONOUGH, W.F., 1989: Chemical and isotopic systematics of oceanic basalts: Implications for mantle compositions and processes. - Magmatism in the ocean basin. - Geol. Soc. Spec. Pap. 42: 313-345.

TOURNON, J., 1984: Magmatismes du Mesozoique a l'actuel en Amérique Centrale: L'exemple de Costa Rica, des ophiolites aux andesites. - 335 págs. Mem. Sc. Terre Univ. Curie, Paris [Tesis PhD].

TOURNON, J., SEYDER, M. \& ASTORGA. A., 1995: Les peridotites du río San Juan (Nicaragua et Costa Rica): jalons d'une suture ultrabasique E-W en Amerique Centrale Meridionale. - C. R. Acad. Sci. Paris, 320 (I) 757-764.

VARGAS, F. \& ALFARO, A., 1992: Presencia de serpentinitas, basaltos alcalinos y rocas volcánicas ácidas en al Zona Norte-Atlántica de Costa Rica. - Rev. Geol. América Central, 14: 105-107.

VOGEL, T. A., PATINO, L.C., ALVARADO, G. E. \& GANS, P. B., 2004: Silicic ignimbrites within the Costa Rican volcanic front: evidence for the formation of continental crust. - Earth Planet. Sci. Let. 226: 149-159.

WEYL, R., 1980: Geology of Central America. - 371 págs. Gebrüder Borntaeger, Stuttgart.

WOODHEAD, J.D., EGGINS, S. \& GAMBLE, J., 1993 High field strenght and transitional elements systematics in island arc and back-arc basin basalts: evidence for multi-phase melt extraction and depleted mantle wedge. - Earth Planet. Sci. Let. 114: 491-504.

ZINDLER, A. \& HART, S., 1986: Chemical geodynamics. Ann. Rev. Earth Planet. Sci. 14: 493-571. 
